\title{
Where there is no research: a bibliometric analysis of health research output from the resource-constrained Bihar state of India
}

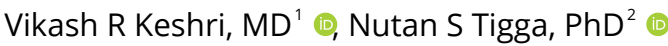 \\ 1 The Centre for Health Policy, Asian Development Research Institute, Patna, India; The George Institute for Global Health, New Delhi, India; Faculty of \\ Medicine, University of New South Wales, Sydney, New South Wales, Australia, ${ }^{2}$ The Centre for Health Policy, Asian Development Research Institute, \\ Patna, India \\ Keywords: health research, bibliometric analysis, health policy, india \\ https://doi.org/10.29392/001c.16633
}

\section{Journal of Global Health Reports}

Vol. 4, 2020

\begin{abstract}
Background
Significant gap exists in health research output globally, both in terms of geographic distribution and priorities. In India, wide inter-state disparity in health research output is reported and eight large states with a combined population of nearly half of India contribute to less than one-tenth of total research output. Bihar is one of the most resource-constrained states in this group with multiple health systems challenges. The objectives of this study were to understand the trend, distribution, focus, actors, and funding sources of health research on Bihar in order to propose policy recommendations.
\end{abstract}

\section{Methods}

A bibliometric analysis was carried out for all PubMed indexed original research papers on health, which is either focused on Bihar or authored by an author from an organization in Bihar. Trend, author affiliation, location, theme, and funding source was analysed by review of either abstract or if required by review of the full text.

\section{Results}

A total of 982 research papers were extracted, out of which $40 \%$ was basic or clinical research and nearly $60 \%$ was public health research. There was an extraordinary surge in research output during the last decade. Clinical subjects (25\%) followed by leishmaniasis (23\%) were the most common theme. Medical institutions (45\%) were the biggest contributor to health research. More than $60 \%$ of papers were authored by a lead author from outside Bihar and the majority do not have a local co-author. 11 leading organizations published more than 35\% of total research papers. 'Leishmaniasis' contributed to more than $35 \%$ of the research output by the author based in Bihar and more than $90 \%$ research output of the leading research institution in Bihar. The majority of the funded research in the last decade was supported by international agencies.

\section{Conclusions}

The health research output from Bihar is very limited. The recent surge in research output is driven by global actors or from actors located in bigger cities and more developed states within India. To strengthen the health research systems, a specific health research policy should be formulated to steward and improve the health research ouput from Bihar.

Health science has made tremendous progress in the last century. As a result, the mortality and morbidity reduced significantly, and the overall life expectancy has increased. The contribution of research has been significant in this direction. The health systems and health research systems are interdependent. ${ }^{1}$ Health research output is also important for proper policy development, health intervention, and service delivery. Unfortunately, a profound gap exists in health research, both in terms of the geographic location of research and funding priorities. It is estimated that only $10 \%$ of funds are used for research on health problems which contribute to $90 \%$ of disease burden globally. Similarly, $90 \%$ of health research is carried out in the countries which account for merely around $10 \%$ of the burden of health problem. ${ }^{2}$ As per a report by the World Health Organization (WHO) in 2018, striking inequalities in health research exists both between countries and between health issues. In terms of health researchers and capacity, the high-income countries have 40 times more health researchers per million population than low-income countries. $^{3}$

At the beginning of this millennium, quality health re- 
search was grossly lacking in India. ${ }^{4}$ There was a significant improvement in health research and public health research output in the first decade of this century. ${ }^{4,5}$ The available evidence also suggests gross geographic disparity in health research output within India. The top ten cities with around $6 \%$ of the population accounted for $76 \%$ of the quality-adjusted research output. The number of papers per million of the population was 0.1 and 2.9 for north Indian states of Bihar and Uttar Pradesh respectively, as compared to 9.3 for the southern state of Karnataka. ${ }^{4}$ Overall the health research output from a group of eight large states with $46 \%$ of the population of India accounted for less than $10 \%$ of total health research output of the country. ${ }^{6}$ Health in India is a subject matter under the jurisdiction of state governments and a significant disparity in health systems and health research output indicate skewed priorities. ${ }^{7}$

Bihar is the third most populated and one of the most resource-constrained state in the country. 8 The per capita income of Bihar was around US $\$ 400$ at constant prices in 2017-18. During the same period, the average per capita income for the southern state of Tamil Nadu and nationally was around US\$1766 and US\$1213 respectively. ${ }^{9}$ The health output and system indicators are also dismal in comparison to other states. ${ }^{10}$ Inadequate teaching and research facilities are another significant bottlenecks of the health sector in Bihar. Very little is known about the overall health research output from the state and its trend over the period. In this context, we analysed the health research output on Bihar to understand the trend, actors, institutions, the focus area of research, and the source of funding. Based on this analysis, we aim to propose recommendations for improving the health research system and stewarding health research priorities.

\section{METHODS}

Bibliometrics is a scientific method to study and describe published literature. Bibliometric analysis is used to produce indicators of national scientific output, and to analyse the output and impact of scientific publications. ${ }^{11}$ We used bibliometric analysis approach to assess the health research output from Bihar. PubMed, an online database of the United States National Library of Medicine is one of the most widely used and authentic bibliographic literature databases for health research. ${ }^{12}$ PubMed databased was purposively selected for the literature review due to its comprehensiveness for health literature. Another important reason for restricting the search to PubMed was to access historical papers and understand historical trends without bias. Health research was defined as research that could be related to health. Health research output was defined as tangible research that was readily available in the public domain. Any paper based on original data collection and its analysis or analysis of already available data was defined as 'original research'. 4,5

All articles reflecting research output from Bihar and indexed in PubMed until August 2019 was part of the sampling universe for this study. We used three search strategies to extract research output from Bihar. Firstly, PubMed was searched for 'Bihar' term in either title or abstract. This search result furnished a list of 1090 articles. Secondly,

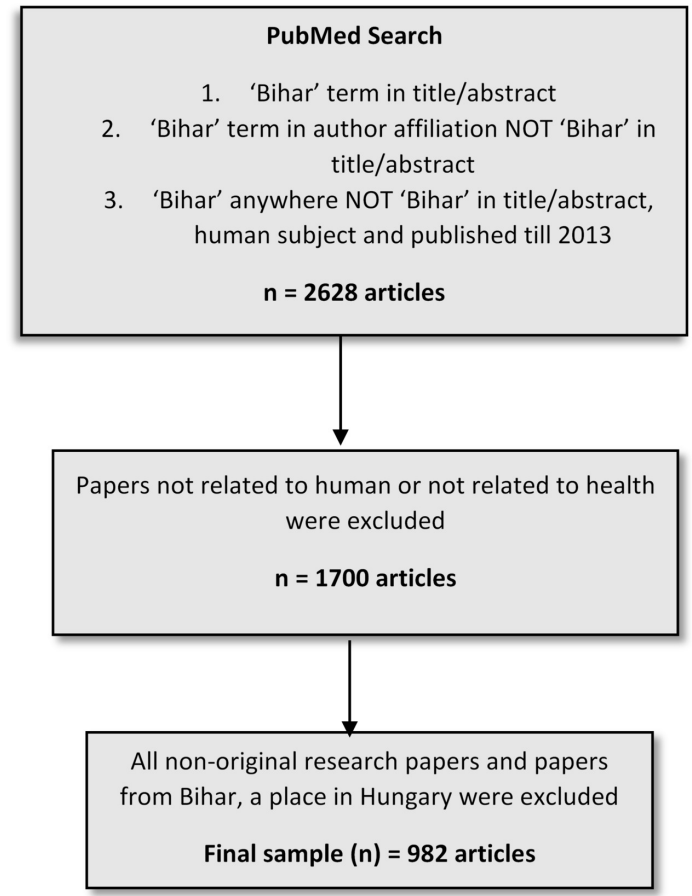

\section{Figure 1. Schematic flow of literature search for bibliometric analysis.}

PubMed was searched for 'Bihar' term in author affiliation, but not in the title or abstract. A total of 1412 articles were available under this category. Until 2013, PubMed displayed the affiliation details of only the first author. ${ }^{11}$ Therefore, we adopted an additional search strategy to capture any missing research papers on Bihar. We searched 'Bihar' term anywhere in the paper focusing on human, published until 2013 without 'Bihar' term listed in the title or abstract. This search strategy showed an additional list of 126 articles. Finally, a total of 2628 articles available for review and possible inclusion for the final analysis. Abstract and wherever necessary full-text of all research articles was reviewed for inclusion. Articles not related to human, health, or healthrelated field and not classified as original research were excluded from the final analysis. Few articles with Bihar in the title or abstract were excluded as these originally belonged to a place with a similar name located in Hungary. After exclusion, a final sample of 982 original health research articles on Bihar was included for detailed review and analysis. Figure 1 depicts the schematic flow of the literature search.

The sampled articles were categorized into two broad domains of Basic or clinical research and public health research. Basic research included all basic research involving experimental or theoretical work. Clinical research included all studies involving clinical cases, issues in the management of patients or laboratory analysis of patient specimens, or a clinical trial or clinical epidemiological study conducted in clinical settings. Public health research includes all articles which deal with population health, demography, epidemiology, health systems and health policies, health financing or economics, environmental health and social determinants of health or any other similar and relevant issues. ${ }^{4}$

We also noted and analysed the year of publication, af- 
filiation and location of the lead author, availability of coauthor from Bihar, affiliation of local co-author, and main theme of the research papers. If an article addressed two major themes, then both were recorded and included for the final analysis. Based on the emerging theme as the analysis progress, we categorised, the research papers into following major themes: clinical subject, leishmaniasis, other infectious diseases including immunization, non-communicable diseases, Reproductive Maternal New-born Child and Adolescent Health (RMNCAH), health system and policies, and tobacco or substance abuse and addiction, and nutrition, and gender or gender-based violence, and miscellaneous.

We also conducted additional analyses to map the source and pattern of funding for research work or paper. Considering the long period for analysis, we restricted the funding analysis to the research papers published during the last 10 years (2010 to 2019). We analysed the source of funding based on the location of the funding body, either national or international. We then categorised the source of funding according to type of organisation. Thereafter we categorised the source of funding according to the type of organisation and conducted analysis of the source of funding for major themes of research papers.

\section{RESULTS}

\section{HISTORY AND TREND IN HEALTH RESEARCH OUTPUT}

A total of 982 original research articles on health were extracted from PubMed which were either based on Bihar or produced by an author from Bihar. Out of these, 402 (40.9\%) were basic or clinical research and 580 (59.1\%) were public health research. The first original research article on Bihar was published in 1927. Till 1950, only 8 original research articles on Bihar were indexed in PubMed. During the next forty years, from 1951 to 1989 , the growth of research on Bihar was equally sluggish and only 67 original research articles were published. In the 1990s, the research output increased marginally with the publication of 66 articles in a decade. The real surge in research output on Bihar was observed in the first decade of this millennium with the number of published original research papers increasing to more than twice as compared to the previous decade. Post-2010, we observed an extraordinary rise in health research output from Bihar. For ten years period from 2010 to 2019, a total of 706 research articles was published during this decade, which is more than $70 \%$ of total health research output on Bihar. In terms of growth, this was more than five times higher in output as compared to the previous decade (Figure 2).

\section{MAJOR THEMES OF RESEARCH}

A substantial proportion (25.3\%) of research articles focused on clinical subjects addressing an issue related to clinical practice. Leishmaniasis was the second most common theme with $23.2 \%$ of research papers. Research on leishmaniasis was distributed almost equally across the two domains of basic or clinical and public health research. The third most common theme of research was one of the subjects of RMNCAH with $14.1 \%$ of total research papers. Around $97 \%$ of the papers on RMNCAH was categorised as public health research, thus making them the most common theme among public health research papers. Other communicable diseases and immunization was the fourth commonest theme (12.1\%), followed by research papers addressing broader issues of either health policy or health systems $(7.1 \%)$. Other common themes of research were nutrition (4.1\%), tobacco or substance abuse or addiction (3.3\%), gender or gender-based violence (1.9\%), and non-communicable diseases (1.8\%). Around $7 \%$ of the papers could not be classified in any of these sub-categories (Figure 3).

\section{THE RESEARCH ACTORS}

The lead author affiliated to a medical institute or hospital produced the highest proportion of research output on Bihar (45.4\%). Most of these research papers were basic or clinical research. The second-largest contributor to research output was non-medical teaching institute, faculty, department, or university (18.9\%). Public health research dominated the research output by these institutions. The third major contributor was independent public research institutes with a contribution of $12.6 \%$, out of which the majority were public health research. Non-Government Organizations (NGOs) including international agencies such as multilateral, bilateral, philanthropic organisations as well as local NGOs together was the fourth largest contributor. These organizations together contributed to $11.9 \%$ of total research output out of which around 95\% was public health research. Other research stakeholders were private research institutes and other organisations or independent researchers, both contributing to less than $5 \%$ of total output. Author affiliation was not specified or was not available for $3.6 \%$ of the sampled articles (Figure 4).

\section{LOCATION OF RESEARCH ACTORS}

The majority of lead authors of research papers based on Bihar were affiliated to an institution or organisation located out of Bihar (61.5\%). But, the majority of the research papers in basic or clinical research domain were led by authors located in Bihar (54.7\%). Researchers based in other Indian states and an institution outside India contributed to $41.2 \%$ and $16.6 \%$ of the research papers on Bihar. Among international authors, the highest proportion was based in the United States of America (USA) (8.4\%), followed by European countries, including the United Kingdom (UK) (5.6\%) and other countries (2.6\%). The location of the lead authors of around $3.8 \%$ of total papers was either not mentioned or was not available (Table 1).

Out of 606 papers with the lead author affiliated to an institution located outside Bihar, the majority (61.7\%) did not have a co-author located in the state. In 258 out of 606 such papers, there was a local co-author from an institute located in Bihar. For basic or clinical research, local co-authors were most commonly based in a medical institute or hospital (47.7\%), followed by NGOs (22.5\%), and independent public research institutes (12.4\%). On the contrarily, for public health research NGOs followed by the medical institution or hospital and independent public research institutes were the most common local collaborators (Table 2). 
Table 1. Location of organization/institution of lead authors of research papers on Bihar

\begin{tabular}{|c|c|c|c|}
\hline \multirow[t]{3}{*}{ Location } & Basic or clinical research & Public health research & Total \\
\hline & $N=402$ & $N=580$ & $N=982$ \\
\hline & $n(\%)$ & $n(\%)$ & $\mathrm{n}(\%)$ \\
\hline Bihar & $220(54.7)$ & $158(27.2)$ & $378(38.5)$ \\
\hline Other Indian States & $151(37.6)$ & $254(43.8)$ & $405(41.2)$ \\
\hline United States of America (USA) & $4(1.0)$ & $78(13.5)$ & $82(8.4)$ \\
\hline Europe including United Kingdom (UK) & $9(2.2)$ & $46(7.9)$ & $55(5.6)$ \\
\hline Other countries & $7(1.7)$ & $18(3.1)$ & $25(2.6)$ \\
\hline Not known & $11(2.7)$ & $26(4.5)$ & $37(3.8)$ \\
\hline
\end{tabular}

Table 2. Type of organization/institution of local co-authors if the lead author is located outside Bihar

\begin{tabular}{|c|c|c|c|}
\hline Type of organization & $\begin{array}{c}\text { Basic or clinical } \\
\text { research } \\
N=118 \\
n(\%)\end{array}$ & $\begin{array}{l}\text { Public health } \\
\text { research } \\
\mathrm{N}=140 \\
\mathrm{n}(\%)\end{array}$ & $\begin{array}{l}\text { Total } \\
\mathrm{N}=258 \\
\mathrm{n}(\%)\end{array}$ \\
\hline Medical college/institute or hospital & $79(67.0)$ & $44(31.4)$ & $\begin{array}{c}123 \\
(47.7)\end{array}$ \\
\hline Non-medical teaching faculty/university or university department & $11(9.3)$ & $7(5.0)$ & $\begin{array}{c}18 \\
(7.0)\end{array}$ \\
\hline Independent research institute (public) & $12(10.2)$ & $20(14.3)$ & $\begin{array}{c}32 \\
(12.4)\end{array}$ \\
\hline Independent research institute (private) & $5(4.2)$ & $5(3.6)$ & $\begin{array}{c}10 \\
(3.9)\end{array}$ \\
\hline $\begin{array}{l}\text { Non-government organization (NGO) (includes, multilateral, bilateral, } \\
\text { philanthropic organization and international and local Non- } \\
\text { Government Organizations) }\end{array}$ & $7(5.9)$ & $51(36.4)$ & $\begin{array}{c}58 \\
(22.5)\end{array}$ \\
\hline Others / independent researcher & $4(3.4)$ & $13(9.3)$ & $\begin{array}{c}17 \\
(6.6)\end{array}$ \\
\hline
\end{tabular}

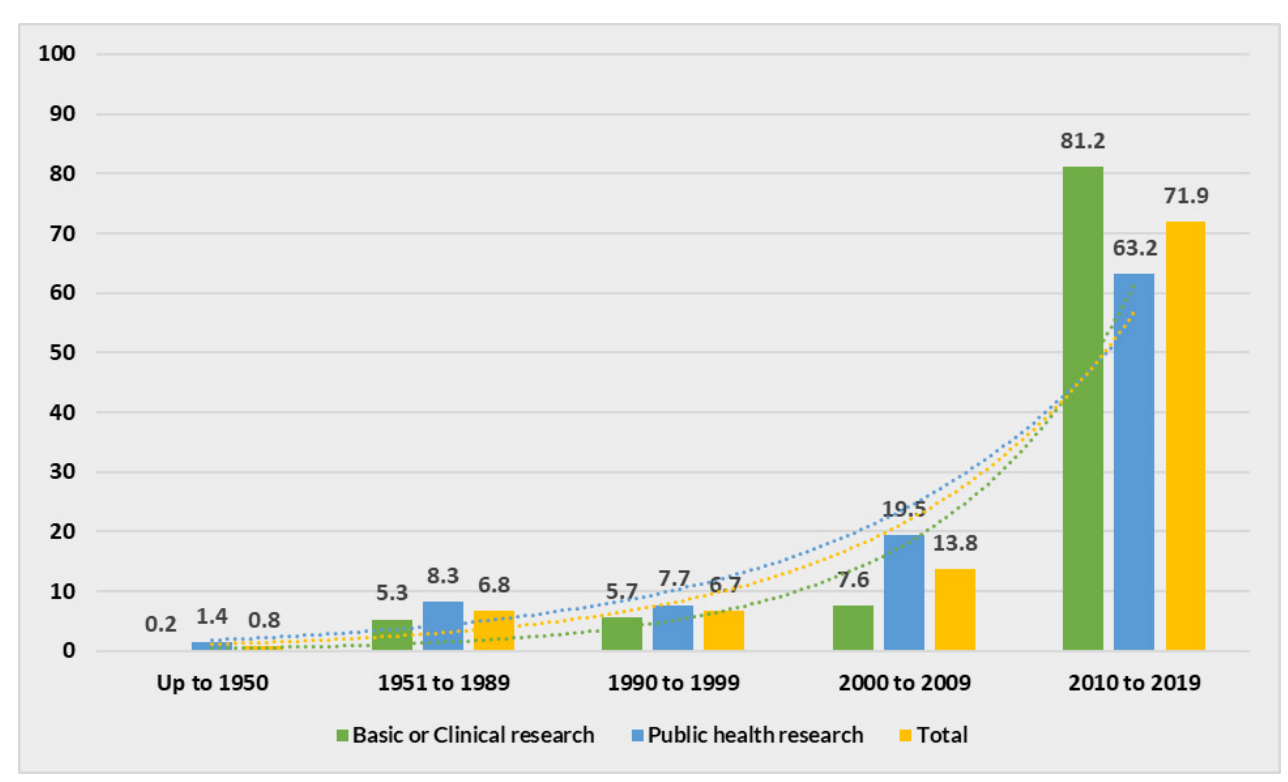

Figure 2. Trend in research output on Bihar over the period. 
Table 3. Top ten research organization as per affiliation of lead authors

\begin{tabular}{|c|c|c|c|c|c|}
\hline \multicolumn{2}{|c|}{ Basic or clinical research $\mathrm{N}=402$} & \multicolumn{2}{|c|}{ Public health research $\mathrm{N}=580$} & \multicolumn{2}{|l|}{ Overall N=982 } \\
\hline Organization & $n(\%)$ & Organization & $\mathrm{n}(\%)$ & Organization & n (\%) \\
\hline $\begin{array}{l}\text { Rajendra Memorial } \\
\text { Research Institute of } \\
\text { Medical Sciences } \\
\text { (RMRIMS), Patna, Bihar }\end{array}$ & $\begin{array}{l}36 \\
(9.0)\end{array}$ & $\begin{array}{l}\text { Rajendra Memorial } \\
\text { Research Institute of } \\
\text { Medical Sciences (RMRIMS), } \\
\text { Patna, Bihar }\end{array}$ & $\begin{array}{c}51 \\
(8.8)\end{array}$ & $\begin{array}{l}\text { Rajendra Memorial } \\
\text { Research Institute of } \\
\text { Medical Sciences } \\
\text { (RMRIMS), Patna, Bihar }\end{array}$ & $\begin{array}{c}87 \\
(8.9)\end{array}$ \\
\hline $\begin{array}{l}\text { All India Institute of } \\
\text { Medical Sciences, Patna, } \\
\text { Bihar }\end{array}$ & $\begin{array}{c}33 \\
(8.2)\end{array}$ & $\begin{array}{l}\text { Banaras Hindu University, } \\
\text { Varanasi, Uttar Pradesh }\end{array}$ & $\begin{array}{c}32 \\
(5.5)\end{array}$ & $\begin{array}{l}\text { Banaras Hindu University, } \\
\text { Varanasi, Uttar Pradesh }\end{array}$ & $\begin{array}{c}61 \\
(6.2)\end{array}$ \\
\hline $\begin{array}{l}\text { Indira Gandhi Institute of } \\
\text { Medical Sciences, Patna, } \\
\text { Bihar }\end{array}$ & $\begin{array}{l}30 \\
(7.5)\end{array}$ & $\begin{array}{l}\text { Public Health Foundation of } \\
\text { India and Indian Institute of } \\
\text { Public Health, Gurugram, } \\
\text { Haryana }\end{array}$ & $\begin{array}{c}21 \\
(3.6)\end{array}$ & $\begin{array}{l}\text { All India Institute of } \\
\text { Medical Sciences, Patna, } \\
\text { Bihar }\end{array}$ & $\begin{array}{c}43 \\
(4.4)\end{array}$ \\
\hline $\begin{array}{l}\text { Banaras Hindu University, } \\
\text { Varanasi, Uttar Pradesh }\end{array}$ & $\begin{array}{l}29 \\
(7.2)\end{array}$ & $\begin{array}{l}\text { International Institute of } \\
\text { Population Sciences, } \\
\text { Mumbai, Maharashtra }\end{array}$ & $\begin{array}{c}13 \\
(2.2)\end{array}$ & $\begin{array}{l}\text { Indira Gandhi Institute of } \\
\text { Medical Sciences, Patna, } \\
\text { Bihar }\end{array}$ & $\begin{array}{c}32 \\
(3.3)\end{array}$ \\
\hline $\begin{array}{l}\text { Patna Medical College and } \\
\text { Hospital, Patna, Bihar }\end{array}$ & $\begin{array}{c}15 \\
(3.7)\end{array}$ & $\begin{array}{l}\text { Patna Medical College and } \\
\text { Hospital, Patna, Bihar }\end{array}$ & $\begin{array}{c}13 \\
(2.2)\end{array}$ & $\begin{array}{l}\text { Patna Medical College and } \\
\text { Hospital, Patna, Bihar }\end{array}$ & $\begin{array}{c}28 \\
(2.9)\end{array}$ \\
\hline $\begin{array}{l}\text { Mata Gujri Memorial } \\
\text { Medical College and LSK } \\
\text { Hospital, Kishanganj, Bihar }\end{array}$ & $\begin{array}{c}13 \\
(3.2)\end{array}$ & Population Council, India & $\begin{array}{c}12 \\
(2.1)\end{array}$ & $\begin{array}{l}\text { Public Health Foundation } \\
\text { of India and Indian } \\
\text { Institute of Public Health, } \\
\text { Gurugram }\end{array}$ & $\begin{array}{c}22 \\
(2.2)\end{array}$ \\
\hline $\begin{array}{l}\text { Narayan Medical College } \\
\text { and Hospital, Rohtas, Bihar }\end{array}$ & $\begin{array}{c}9 \\
(2.2)\end{array}$ & $\begin{array}{l}\text { University of California, } \\
\text { United States of America }\end{array}$ & $\begin{array}{c}12 \\
(2.1)\end{array}$ & $\begin{array}{l}\text { Mata Gujri Memorial } \\
\text { Medical College and LSK } \\
\text { Hospital, Kishanganj, Bihar }\end{array}$ & $\begin{array}{c}17 \\
(1.7)\end{array}$ \\
\hline $\begin{array}{l}\text { Mithila Minority Dental } \\
\text { College and Hospital, } \\
\text { Darbhanga, Bihar }\end{array}$ & $\begin{array}{c}8 \\
(2.0)\end{array}$ & $\begin{array}{l}\text { Emory University, United } \\
\text { State of America }\end{array}$ & $\begin{array}{c}11 \\
(1.9)\end{array}$ & $\begin{array}{l}\text { All India Institute of } \\
\text { Medical Sciences, New } \\
\text { Delhi }\end{array}$ & $\begin{array}{c}15 \\
(1.5)\end{array}$ \\
\hline $\begin{array}{l}\text { King George's Medical } \\
\text { University, Lucknow, Uttar } \\
\text { Pradesh }\end{array}$ & $\begin{array}{c}6 \\
(1.5)\end{array}$ & $\begin{array}{l}\text { School of Preventive } \\
\text { Oncology, Patna, Bihar }\end{array}$ & $\begin{array}{c}11 \\
(1.9)\end{array}$ & Population Council, India & $\begin{array}{c}14 \\
(1.4)\end{array}$ \\
\hline $\begin{array}{l}\text { All India Institute of } \\
\text { Medical Sciences, New } \\
\text { Delhi /Katihar Medical } \\
\text { College and Hospital, } \\
\text { Katihar, Bihar /Nalanda } \\
\text { Medical and Hospital, } \\
\text { Patna, Bihar }\end{array}$ & $\begin{array}{c}5 \\
(1.2)\end{array}$ & $\begin{array}{l}\text { All India Institute of Medical } \\
\text { Sciences, New Delhi / All } \\
\text { India Institute of Medical } \\
\text { Sciences, Patna, Bihar } \\
\text { /CARE India, Patna, Bihar } \\
\text { /Healis Sekhsaria Institute } \\
\text { of Public Health, Mumbai, } \\
\text { Maharashtra /Médecins } \\
\text { sans frontiers (MSF), India }\end{array}$ & $\begin{array}{c}10 \\
(1.7)\end{array}$ & $\begin{array}{l}\text { International Institute of } \\
\text { Population Sciences, } \\
\text { Mumbai, Maharashtra / } \\
\text { Narayan Medical College } \\
\text { and Hospital, Rohtas, Bihar }\end{array}$ & $\begin{array}{c}13 \\
(1.3)\end{array}$ \\
\hline Total & $\begin{array}{c}194 \\
(48.2)\end{array}$ & & $\begin{array}{c}228 \\
(39.3)\end{array}$ & & $\begin{array}{c}345 \\
(35.1)\end{array}$ \\
\hline
\end{tabular}

\section{LEADING ORGANIZATIONS FOR HEALTH RESEARCH}

Overall, 11 organisations or institutions are among the top ten producers of health research output on Bihar. Out of these 6 are located within the state and 5 outsides of the state. These organisations together contribute to around $35.1 \%$ of the total research output. For basic or clinical research, 12 organisations are among the top ten research producers, with 8 located within the state and 4 outside. These organizations together contribute to $48.2 \%$ of total basic or clinical research output. For public health research, 14 organizations are among the top ten research producers with a combined research output of $39.3 \%$. Among the leading organisation on public health research, five are located within Bihar, seven in other states, and two in the USA (Table 3).
The top five leading research organisations produced more than $25 \%$ of overall research output. Leishmaniasis was the most common theme of the papers produced by the top five research institutes. The majority of local co-authors for research led by external authors were based in only 10 organizations.

\section{THE SOURCE OF FUNDING FOR RESEARCH}

One of the important factors influencing the research work and output is the availability of funding to conduct and publish research. As observed above, there was an acute surge in research output on Bihar in the last decade with more than $70 \%$ of research output being reported during this period. We could extract funding information for 346 (49.1\%) of the total of 706 papers published during this pe- 


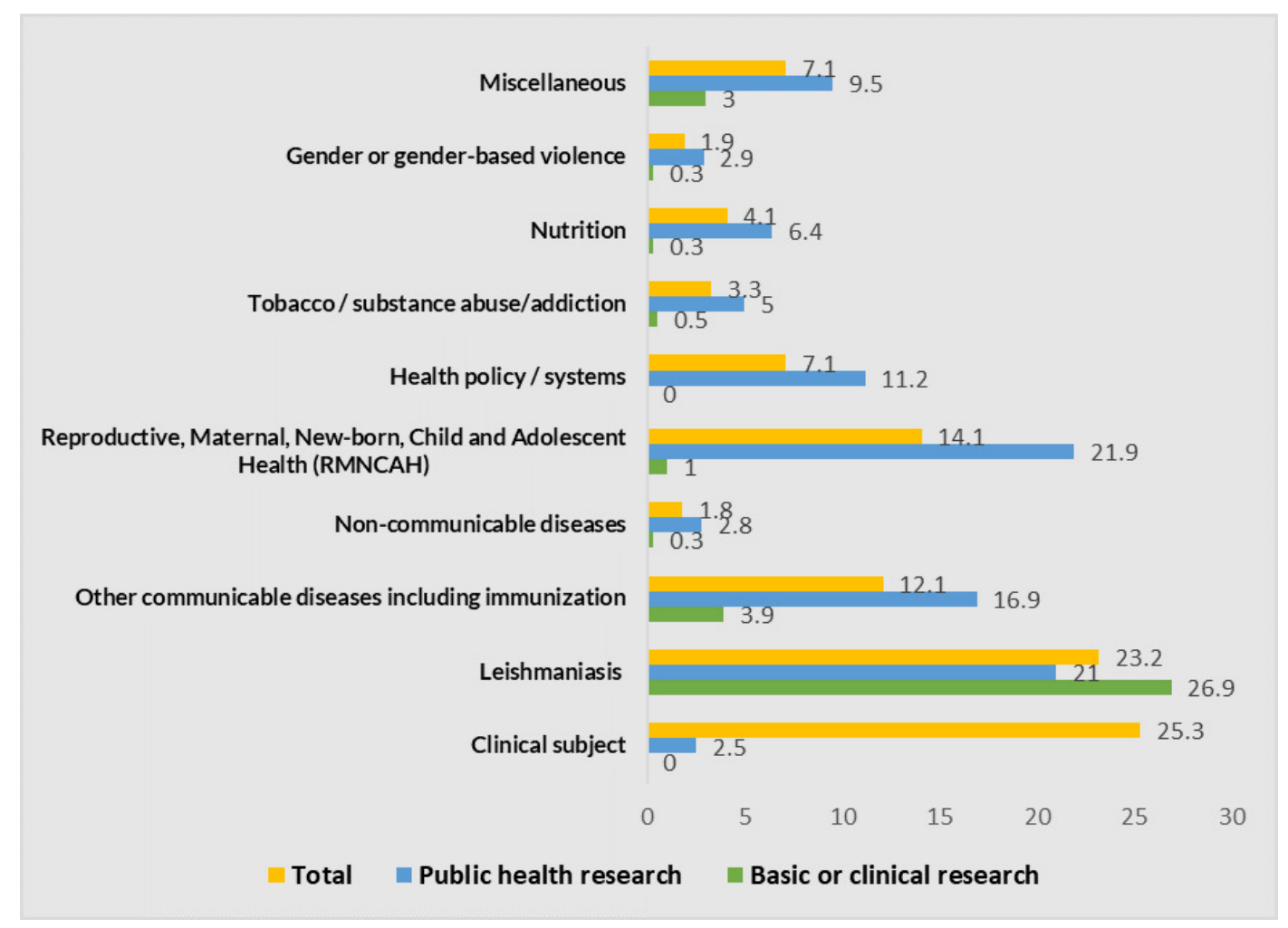

Figure 3. Major theme of health research papers on Bihar.
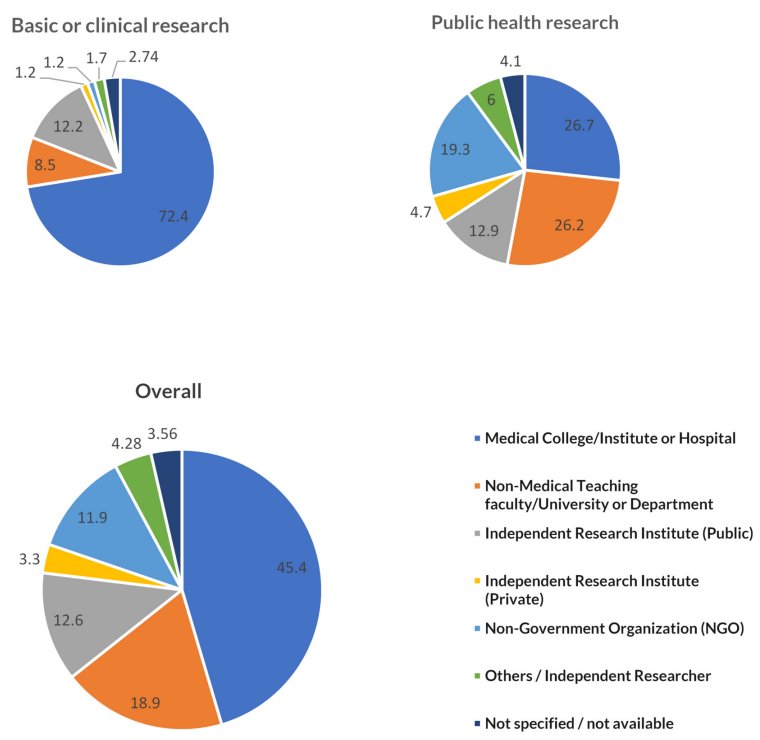

Figure 4. Type of organizational affiliation of lead authors for research papers on Bihar.

riod (2010 to 2019). Other research work was either not funded or funding information was not available with the publication. Out of 346 research papers, $71.7 \%$ were funded by an international source and only $28.3 \%$ received funding from a national source. The most common funding source was the global philanthropic organizations (29.8\%), followed by foreign government institutions or organisations (21.7\%), Indian government bodies (21.4\%), international multilateral organisations (14.7\%), and other sources

\section{(12.4\%) (Figure 5).}

More than $90 \%$ of the research work funded by international sources was in the public health domain, while the proportion of public health research funded by national sources was only $40 \%$. Leishmaniasis was the most common subject funded by both national (53.1\%) and international (31.5\%) funding sources. International sources also commonly funded research on RMNCAH (28.2\%), other communicable diseases (14.9\%), others (14.5\%), and health sys- 


\begin{tabular}{|c|c|c|}
\hline \multirow[b]{2}{*}{ Domain } & \multicolumn{2}{|c|}{ Source of funding } \\
\hline & $\begin{array}{c}\text { International source } \\
(\mathrm{N}=248) \\
\mathrm{n}(\%)\end{array}$ & $\begin{array}{c}\text { National source } \\
(\mathrm{N}=98) \\
\mathrm{n}(\%)\end{array}$ \\
\hline Basic or clinical research & $22(8.9)$ & $59(60.2)$ \\
\hline Public health research & $226(91.1)$ & $39(39.8)$ \\
\hline \multicolumn{3}{|l|}{ Major theme } \\
\hline Leishmaniasis & $78(31.5)$ & $52(53.1)$ \\
\hline Other communicable diseases & $37(14.9)$ & $6(6.1)$ \\
\hline Reproductive, Maternal, New-born, Child and Adolescent Health (RMNCAH) & $70(28.2)$ & $2(2.0)$ \\
\hline Health policy/systems & $27(10.9)$ & 0 \\
\hline Others /clinical & $36(14.5)$ & $28(28.6)$ \\
\hline
\end{tabular}

tems (10.9\%), but funding on these themes by national funding sources was very low (Table 4).

\section{A SPECIAL CASE OF LEISHMANIASIS}

Leishmaniasis is an endemic disease with a very high incidence in Bihar. More than $80 \%$ of the total cases of leishmaniasis in India are reported from Bihar. ${ }^{12}$ Our findings suggest leishmaniasis to be the main theme of health research output from the state with nearly a quarter of total research papers addressing this issue. The majority of the papers on leishmaniasis are authored by a lead author located in $\mathrm{Bi}-$ har (52.2\%) followed by authors based in other Indian states (29.5\%) and out of India (9\%) (Figure 6). A total of 378 articles was authored by a lead author based in Bihar out of which 131 (34.7\%) addressed leishmaniasis. Most of the papers (91.9\%) produced by the leading research organization (Rajendra Memorial Research Institute of Medical Sciences) addressed leishmaniasis as one of the themes. Around $70 \%$ of papers authored by researchers affiliated with the second leading research organization (Banaras Hindu University, Varanasi) focused on leishmaniasis as one of the themes.

\section{DISCUSSION}

In this paper, we have analysed and presented the health research output from the resource-constrained Bihar state in India by undertaking bibliometrics analysis of health research papers indexed in PubMed. The decision to use the PubMed database for this study was based on evidence and experience of prior similar published literature. ${ }^{4-6,12}$ Indexing in PubMed is also considered as one of the quality measures of medical and public health research journals. ${ }^{13}$ Our analysis is probably the first attempt to understand the health research output at the sub-national level in India. Health being a state subject in India necessitate such analysis at the sub-national level. ${ }^{4}$ The findings of this study can help significantly in understanding the role of health research in the overall health systems development in resource-constrained settings. The methodology and findings of this study can also be used to understand research

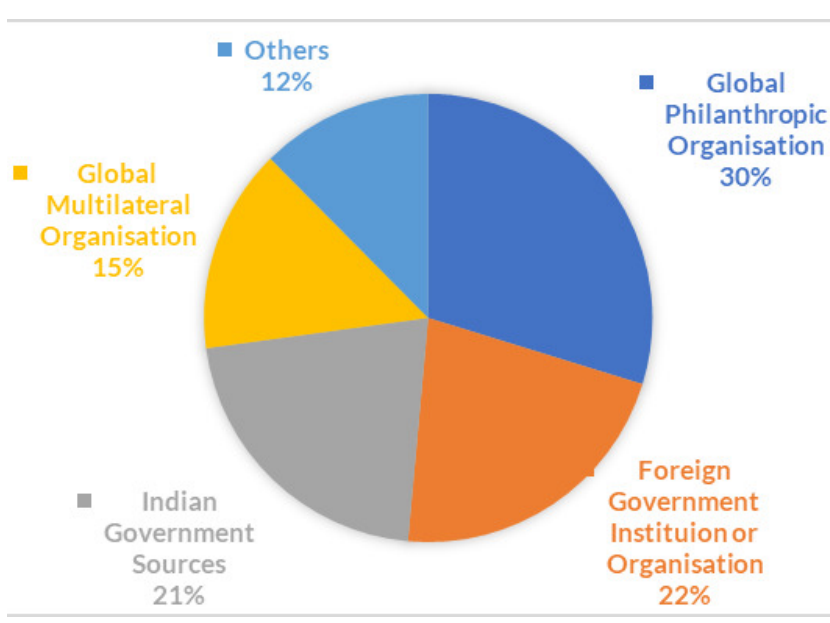

Figure 5. Major source of funding for research on Bihar from 2010 to 2019.

paucity and its implications in other similar settings globally.

The results show the limited health research output from Bihar. Original research in health seems to be comparatively a recent phenomenon, as indicated by a surge in published research papers in the last decade. The overall trend of health research output in India also exhibits similar trends. A study published in 2004 found gross inadequacy in the health research output in comparison to the magnitude and distribution of diseases in India. Moreover, the public health research output was 11 times lower than basic or clinical research. ${ }^{4}$ In 2008 , the number of public health research output in India increased significantly as compared to 2001 but with increasing output the inequity in terms of priority of research theme, geographic settings of research and location of researchers also increased within the country. ${ }^{4,5}$ Similar inequity in research output is also observed in other low and middle-income countries (LMIC) context in the African region. ${ }^{14}$ Such global disparity is also due to the availability and capacity of health researchers. As per an analysis by WHO, there were 363 health researchers per million population in high-income countries in comparison 


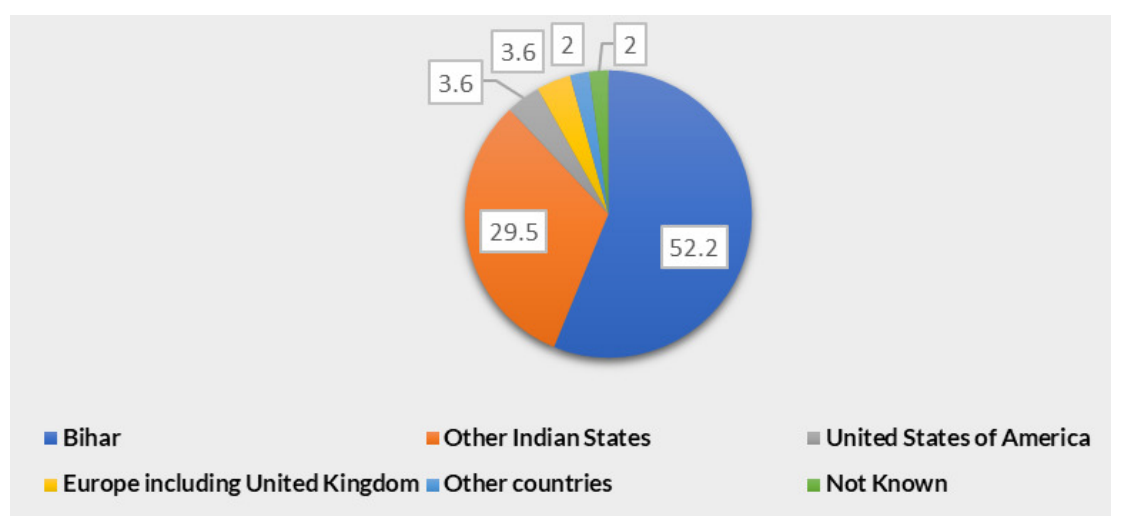

Figure 6. Location of lead authors for research focused on leishmaniasis.

\section{to 55 in LMICs and 5 in low-income countries. ${ }^{3}$}

Previous evidence has documented dominance of clinical research in the arena of health research in India. ${ }^{4-6}$ On the contrary, we found that the public health research output is higher than the clinical research output in Bihar. The research output on non-communicable diseases, nutrition, gender, and injuries was particularly scarce. As per the India State-Level Disease Burden estimates, the top 15 causes of Disability Adjusted Life Years (DALYs) in Bihar changed significantly from 1990 to 2016, with non-communicable diseases and nutritional deficiency becoming more significant. ${ }^{15}$ Bihar is undergoing an epidemiological transition; however, we found a huge gap between the disease burden estimates and focus of health research output. Such disparity was also observed in research output from India and globally. ${ }^{2-4}$

Our findings also corroborate that medical institutions are the largest contributors to health research, especially for basic or clinical research. Public health research is produced mainly by non-medical institutions, independent public and private research institutes, and NGOs. This result points towards two important concerns: the poor capacity to conduct large population-based research and/or lack of funding opportunities to carry out the populationbased primary health research. We also found that the majority of public health research papers are led by researchers based out of Bihar and less than half of these papers had a local co-author. This finding implies that besides capacity and funding, the collaborative opportunity is also limited to local researchers based in the state.

We also found that the ten leading research organizations dominate the health research output on Bihar and most of these leading organizations are located outside the state. Another important finding was funding by international sources being more common than funding by national sources. Getting funds from international sources is a competitive process and often highly dependent on existing capacity and demonstrated research credentials. It can be interpreted that due to limited capacity, the local research institutions get a limited opportunity for such funding. The funding by the national source was mainly by the central government funding body, the Indian council of medical research, which was mostly restricted to its constituent institutions.
The above findings reiterate the potential limitations of institutions and infrastructure, availability of funding and collaborative opportunities, and capacity of researchers in the local health research system in Bihar. The overall findings also reflect low priority and the very limited stewardship for health research in the state. To improve the dismal health research scenario in Bihar, the state should evolve a definite health research policy. Such a policy should be aimed to address three complementary strategies for improving health research systems in the state, these are demand, supply, and environment of research. Here, demand refers to the role of policymakers and senior academics in demanding for the relevant research base to take a policy decision. Supply indicates the adequacy of the research supply to meet the demands in terms of infrastructure, research capacity, funding, and quality monitoring. The environment implies ensuring a conducive environment for demand and supply to work optimally. ${ }^{2}$ One of the ideal ways to approach such reform in health research systems is to adopt and implement the WHO strategy for health research. ${ }^{13}$ This strategy recommends five actions to strengthen the health research system in any state. These are strengthening of research culture (organization), reinforcement of research on priority health needs (priorities), provision of support to strengthen health research system within the state (capacity), promoting good practice in research (standards), and strengthening the link between policy, practice and research (translation). For the success of such reforms, the overall stewardship of the department of health is vital. To strengthen such stewardship capacity, a separate body should be established to steer health research. Such a body should ideally be led by an experienced health researcher who can provide leadership to steward the growth of the research ecosystem in the state. In the long run, health research should also be embedded in all existing policies and programmes on health. The combination of approaches mentioned above with a feasible milestone and clear timeline can strengthen the health research system and contribute significantly to overall health system development.

This study also has few limitations, mostly related to the bibliometric analysis. We have used published literature, indexed in PubMed for analysing research output. Although PubMed is one of the most comprehensive databases on 
health research, yet many health-related papers from the field of economics, social sciences, political science and development studies may not necessarily be indexed in this database. Thus, some of the articles related to health and published in journals not indexed by PubMed might have been missed from our final sample. A subsequent social science bibliometric analysis would be useful to fill this gap. Similarly, some Indian journals publishing original health research are not indexed in PubMed. The IndMED search database for such Indian journals could not be accessed despite repeated attempts. Another important limitation can be the assessment and affiliation of local co-authors. PubMed provided affiliation details of only the first authors until 2013. We adopted an additional search strategy to overcome this limitation, yet a small proportion of papers could have been missed. The funding source for many articles was also not available with the publication. Despite these limitations, our analysis is one of the most comprehensive and pioneer work on sub-national level health research output in India. In a big country like India, such an analysis is important to assess the health research system at the state level. The approach adopted in this study can be easily replicated in other states of India and for similar contexts globally. Thus, the knowledge generated can contribute to the overall development of health systems in similar settings globally.

\section{CONCLUSIONS}

The health research output from Bihar is very limited and not aligned with the priorities of health systems, and disease burden. An acute surge in health research output is noticed in the recent decade. The findings also reflect the dominance of a few research organizations, research actors, and limited priority areas of research. The contribution of local research organisations in public health is very limited. All these factors call for immediate policy action by the state-level policymakers to improve health research system in the state. Lessons from such an effort may have implications for other states in India and other similar settings globally.
Acknowledgements: This study is based on analysis of data from a publicly available database. Therefore, this study is exempted from ethical review as per the Indian Council for Medical Research (ICMR), India guideline on bio-medical and health research involving human subjects published in 2017.

Availability of data and materials: The datasets used and/ or analysed during the current study are available from the corresponding author on reasonable request.

Funding: This study was funded through a grant from the Bill and Melinda Gates Foundation. The funding body was not involved in the design of the study, data collection, analysis, and interpretation of data or writing of the manuscript.

Authorship contributions: VRK conceptualized and designed the study anddeveloped literature search strategies. NST carried out the literature search and extracted the data. NST and VRK carried out the analysis. VRK and NST interpreted the data. VRK drafted the manuscript and NST provided her inputs into it. Both authors read and approved the final manuscript.

Competing interests: The authors completed the Unified Competing Interest form at www.icmje.org/coidisclosure.pdf (available upon request from the corresponding author), and declare no conflicts of interest.

\section{Correspondence to:}

Dr. Vikash R Keshri,

The Centre for Health Policy,

Asian Development Research Institute

Patna, India, vrkeshri@gmail.com 


\section{REFERENCES}

1. World Health Organization. World Report on Knowledge for Better Health - Strengthening Health Systems. Geneva: WHO; 2004. http://www.who.int/rp c/meetings/world report on knowledge for better he alth.pdf?ua=1. Accessed January 28, 2020.

2. Global Forum for Health Research. The 10/90 Report in Health Research 2003-04. Geneva: Global Forum for Health Research; 2004.

3. World Health Organization. One year on, Global Observatory on Health R\&D identifies striking gaps and inequalities. February 2020. https://www.who.in t/features/2018/health-research-and-development/e n/. Accessed August 18, 2020.

4. Dandona L, Sivan YS, Jyothi MN, Bhaskar VU, Dandona R. The lack of public health research output from India. BMC Public Health. 2004;4(1). doi:10.118 6/1471-2458-4-55

5. Dandona L, Raban MZ, Guggilla RK, Bhatnagar A, Dandona R. Trends of public health research output from India during 2001-2008. BMC Med. 2009;7(1). do $\mathrm{i}: 10.1186 / 1741-7015-7-59$

6. Kalita A, Shinde S, Patel V. Public health research in India in the new millennium: A bibliometric analysis. Glob Health Action. 2015;8(1):27576. doi:1 $\underline{0.3402 / g h a . v 8.27576}$

7. Government of India. The Constitution of India. http s://www.india.gov.in/sites/upload files/npi/files/coi c ontents.pdf. Accessed January 2020.

8. Census of India. States Census 2011. New Delhi: Office of the Registrar General \& Census

Commissioner; 2011. https://www.census2011.co.in/s tates.php. Accessed January 28, 2020.
9. Government of Bihar. Economic Survey of Bihar (2018-19). Patna: Department of Finance; 2019. htt p://finance.bih.nic.in/Reports/Economic-Survey-201 9-EN.pdf. Accessed January 28, 2020.

10. Government of India. Healthy States Progressive India: Report on the Ranks of States and Union Territories, NITI Aayog. New Delhi: Government of India; 2019. http://social.niti.gov.in/uploads/sample/ health_index_report.pdf. Accessed January 28, 2020.

11. Lewison G, Devey ME. Bibliometric methods for the evaluation of arthritis research. Rheumatology. 1999;38(1):13-20. doi:10.1093/rheumatology/38.1.13

12. PubMed Help. National Center for Biotechnology Information (US). https://www.ncbi.nlm.nih.gov/book s/NBK3827/. Accessed January 28, 2020.

13. Natarajan $S$. The relevance of indexed journals. Indian J Ophthalmol. 2016;64(5):331. doi:10.4103/030 $\underline{1-4738.185583}$

14. Uthman OA, Wiysonge CS, Ota MO, et al. Increasing the value of health research in the WHO African Region beyond 2015-reflecting on the past, celebrating the present and building the future: A bibliometric analysis. BMJ Open.

2015;5(3):e006340-e006340. doi:10.1136/bmjopen-20 $\underline{14-006340}$

15. India State-Level Disease Burden Initiative Collaborators. Nations within a nation: Variations in epidemiological transition across the states of India, 1990, 2013 and 2016 in the Global Burden of Disease Study. Lancet. 2017;390:2437-2460. 